\title{
The Effect of Basic Technical Training on Performance Capabilities of Young Soccer Players
}

\author{
Yossi Haleva, Yoav Meckel \\ The Academic College at Wingate, Wingate Institute, Netanya, Israel \\ Email: meckel@wincol.ac.il
}

How to cite this paper: Haleva, Y., \& Meckel, Y. (2020). The Effect of Basic Technical Training on Performance Capabilities of Young Soccer Players. Advances in Physical Education, 10, 19-30.

https://doi.org/10.4236/ape.2020.101003

Received: November 28, 2019

Accepted: January 6, 2020

Published: January 9, 2020

Copyright $\odot 2020$ by author(s) and Scientific Research Publishing Inc. This work is licensed under the Creative Commons Attribution International License (CC BY 4.0).

http://creativecommons.org/licenses/by/4.0/

\begin{abstract}
It was suggested that training of players at young ages should focus on the development of basic technical skill since optimal responses to such training can be obtained at these ages. The aim of the present study was to examine the inclusion of basic technical exercises to regular soccer training on performance capabilities in young players. Twenty-eight young (12 - $14 \mathrm{yrs)} \mathrm{players} \mathrm{were}$ assigned to either a soccer training group that performed specific soccer training (SG), or a group that combined soccer and basic technical training (TG). Both groups completed two similar sets of tests prior to and following nine weeks of training. While SG training led to a significant improvement only in the $20 \mathrm{~m}$ shuttle run aerobic test ( $645 \pm 368$ vs. $738 \pm 308 \mathrm{~m}, p<0.05)$, TG training led to a significant improvement in $10 \mathrm{~m}(2.05 \mathrm{vs} .2 .00 \mathrm{sec})$ and $30 \mathrm{~m}(5.13 \mathrm{vs}$. $5.07 \mathrm{sec}$ ) sprint times ( $p<0.05$ for both). However, a significant reduction in the $4 \times 10$ m agility test ( 9.99 vs. $10.20 \mathrm{sec}, p<0.01$ ) was found for the TG. Neither of the training programs had a significant effect on the long-jump power test. The findings demonstrate the complexity and the various requirements of soccer, suggesting that in order to comply with all game requirements technical training program for young players may be more efficient if implemented together with resistance-and endurance-type exercises.
\end{abstract}

\section{Keywords}

Fitness, Resistance, Speed, Agility, Efficiency, Aerobic Capacity

\section{Introduction}

Although soccer players perform low-intensity activities such as walking or jogging during the game, it was shown that quickness and speed are qualities that 
are very often required by the players to perform anaerobic-type activities such as sprinting, turning or changing running direction (Stølen et al., 2005). Although these activities account for only $8 \%-12 \%$ of the total distance covered in a soccer match, it was found that they are essential to a soccer match's outcome (Rampinini et al., 2007).

In adult players, numerous types of training methods are known to improve the performance of anaerobic-type activities. High-intensity intervals, plyometric drills, and weight lifting are examples of such training (Markovic et al., 2007; Meckel et al., 2012). However, due to the high impact of these training methods on the skeletal, neuromuscular, and energy systems, their use among young children is not very common. In addition, since various activities in soccer are complicated and require a high level of motor control, it was suggested that players at young ages ( 9 - 14 yrs) should focus on basic technical skill training rather than on the "common adult-training" methods (Branta, Haubenstricker, \& Seefeldt, 1984; Yasumitsu \& Nogaw, 2013). It was argued that basic technical training sessions are appropriate for young athletes, as they are important and useful for the development of basic motor skills at these ages. Such a notion relies on the concept that technical exercises should be conducted in the early phases of relies growth and development-during the so-called "sensitive phase" when the optimum responses to basic skill exercises can be obtained from the young trainees (de Villarreal et al., 2015; Naughton et al., 2000). Then afterwards, as the players grow up, soccer-specific skills will be easier to train and acquire. Indeed, Velickovic (2012) found significant correlations between general coordination variables (speed, agility) and specific skills of young soccer players. Similar results were found by Bojić \& Palović (2015), showing significant relationships between coordination abilities (sprinting, jumping, sideway steps) and specific motor skills of young (age 12 - $14 \mathrm{yrs}$ ) female handball players.

Despite these conclusions and suggestions, it is not clear whether the inclusion of basic technical training among players is superior to specific soccer training alone, for improving physical performance such as sprinting, jumping, and change of direction, which have found to be important in soccer (Malina, Ribeiro, \& Aroso, 2007). This question is particularly important among the young players, who are expected to develop new skills. The purpose of the present study, therefore, was to investigate the effects of a training program that includes regular soccer training combined with basic technical training, as compared to a training program that includes soccer training alone, on selected performance capabilities of young soccer players. We hypothesized that the inclusion of basic technical training with regular soccer training would result in substantial improvements in performance capabilities (speed, agility, power, and endurance) compared to soccer training alone.

\section{Method}

\subsection{Participants}

Thirty-five young male soccer players (age range 12 - 14), members of two teams 
from the youth soccer league during the 2018/2019 competitive season, began the study. However, seven of the 35 players were excluded from the final analysis. The $20 \%$ dropout rate occurred due to missed follow-up tests, injuries, or absence from more than $10 \%$ of the training sessions. Thus, only 28 participants were included in the final analysis. All the players played in the same league and had 3 - 4 years of experience in soccer training. None of the participants took any prescription medications or food supplements during the training or testing. Standard calibrated scales and stadiometers (Seca, 707, Germany) were used to determine body mass and height. The participants and their parents were informed of the experimental procedures and risks, and signed an informed consent prior to participation. The Research Ethics Committee of the Academic College at Wingate approved the study.

\subsection{Design}

The study lasted eleven weeks and consisted of one week of pre-testing, nine weeks of training, and one week of post-testing. The study was conducted from November until January-the middle of the competitive season. Using a controlled study design, players were randomly assigned to one of two training groups after matching for sprinting ability according to pre-test results. One group performed regular soccer training with the addition of basic technical drills (TG). The other group performed only regular soccer training (SG). Both training groups performed four training sessions per week and played during the weekend. However, while the TG performed two sessions of soccer training combined with technical drills and two sessions of only soccer training, the SG performed four sessions of only soccer training. Each training session was matched between the groups for the total training time. In order to achieve complete matching time in physical activity between groups, participants were asked to avoid any leisure physical activity during the study other than the study training. Pre- and post-training performance assessment included $10 \mathrm{~m}$ and $30 \mathrm{~m}$ sprint runs for speed assessment, a maximal standing long jump for power assessment, a $4 \times 10 \mathrm{~m}$ shuttle run agility test, and a $20 \mathrm{~m}$ shuttle run ("yo-yo" test) for aerobic capacity assessment.

\section{Training Programs}

Table 1 presents the training protocols of the two groups throughout the nine-week training period. The two weekly training sessions of the TG, that combined soccer and technical practice, included 25 - $30 \mathrm{~min}$ of technical drills, and followed by $50-60 \mathrm{~min}$ of regular soccer training. The additional weekly sessions for this group included $80-90 \mathrm{~min}$ of only regular soccer training. The SG performed 80 - 90 min of only soccer training in all four training sessions. The regular soccer training for both groups included specific soccer drills such as passing, kicking, stooping and bouncing the ball in various forms. Both training groups gradually increased training volume over the weeks in an attempt to prevent fatigue or injuries among the participants. 
Table 1. The training protocol sessions for the technical group ((a) technical training) and the SG ((b) soccer training).

(a)

\begin{tabular}{|c|c|c|c|c|c|c|c|c|}
\hline \multirow{2}{*}{$\begin{array}{c}\text { Weeks } \\
\text { Exercise }\end{array}$} & \multicolumn{2}{|c|}{ Week 1} & \multicolumn{2}{|c|}{ Week 2} & \multicolumn{2}{|c|}{ Week 3} & \multicolumn{2}{|c|}{ Week 4} \\
\hline & Ses 1 & Ses 2 & Ses 3 & Ses 4 & Ses 5 & Ses 6 & Ses 7 & Ses 8 \\
\hline Low skips & $2 \times 10 \mathrm{~m}$ & $2 \times 10 \mathrm{~m}$ & $2 \times 10 \mathrm{~m}$ & $3 \times 10 \mathrm{~m}$ & $2 \times 10 \mathrm{~m}$ & $3 \times 10 \mathrm{~m}$ & $2 \times 10 \mathrm{~m}$ & $3 \times 10 \mathrm{~m}$ \\
\hline Heel kicks & $2 \times 10 \mathrm{~m}$ & $2 \times 10 \mathrm{~m}$ & $2 \times 10 \mathrm{~m}$ & $3 \times 10 \mathrm{~m}$ & $2 \times 10 \mathrm{~m}$ & $3 \times 10 \mathrm{~m}$ & $2 \times 10 \mathrm{~m}$ & $3 \times 10 \mathrm{~m}$ \\
\hline High skips & $2 \times 10 \mathrm{~m}$ & $2 \times 10 \mathrm{~m}$ & $2 \times 10 \mathrm{~m}$ & $3 \times 10 \mathrm{~m}$ & $2 \times 10 \mathrm{~m}$ & $3 \times 10 \mathrm{~m}$ & $2 \times 10 \mathrm{~m}$ & $3 \times 10 \mathrm{~m}$ \\
\hline Running & $2 \times 10 \mathrm{~m}$ & $2 \times 10 \mathrm{~m}$ & $2 \times 10 \mathrm{~m}$ & $3 \times 10 \mathrm{~m}$ & $2 \times 10 \mathrm{~m}$ & $3 \times 10 \mathrm{~m}$ & $2 \times 10 \mathrm{~m}$ & $3 \times 10 \mathrm{~m}$ \\
\hline \multirow[t]{2}{*}{ Total d. } & $80 \mathrm{~m}$ & $80 \mathrm{~m}$ & $80 \mathrm{~m}$ & $120 \mathrm{~m}$ & $80 \mathrm{~m}$ & $120 \mathrm{~m}$ & $80 \mathrm{~m}$ & $120 \mathrm{~m}$ \\
\hline & \multicolumn{2}{|c|}{ Week 5} & \multicolumn{2}{|c|}{ Week 6} & \multicolumn{2}{|c|}{ Week 7} & \multicolumn{2}{|c|}{ Weeks 8 - 9} \\
\hline Exercise & Ses 9 & Ses 10 & Ses 11 & Ses 12 & Ses 13 & Ses 14 & Ses 15 & Ses 16 \\
\hline Low skips & $2 \times 15 \mathrm{~m}$ & $2 \times 15 \mathrm{~m}$ & $2 \times 15 \mathrm{~m}$ & $2 \times 15 \mathrm{~m}$ & $2 \times 15 \mathrm{~m}$ & $2 \times 15 \mathrm{~m}$ & $2 \times 15 \mathrm{~m}$ & $2 \times 15 \mathrm{~m}$ \\
\hline Heel kicks & $2 \times 15 \mathrm{~m}$ & $2 \times 15 \mathrm{~m}$ & $2 \times 15 \mathrm{~m}$ & $2 \times 15 \mathrm{~m}$ & $2 \times 15 \mathrm{~m}$ & $2 \times 15 \mathrm{~m}$ & $2 \times 15 \mathrm{~m}$ & $2 \times 15 \mathrm{~m}$ \\
\hline High skips & $2 \times 15 \mathrm{~m}$ & $2 \times 15 \mathrm{~m}$ & $2 \times 15 \mathrm{~m}$ & $2 \times 15 \mathrm{~m}$ & $2 \times 15 \mathrm{~m}$ & $2 \times 15 \mathrm{~m}$ & $2 \times 15 \mathrm{~m}$ & $2 \times 15 \mathrm{~m}$ \\
\hline Running & $2 \times 15 \mathrm{~m}$ & $3 \times 15 \mathrm{~m}$ & $3 \times 15 \mathrm{~m}$ & $4 \times 15 \mathrm{~m}$ & $4 \times 15 \mathrm{~m}$ & $5 \times 15 \mathrm{~m}$ & $5 \times 15 \mathrm{~m}$ & $6 \times 15 \mathrm{~m}$ \\
\hline Total d. & $120 \mathrm{~m}$ & $135 \mathrm{~m}$ & $135 \mathrm{~m}$ & $150 \mathrm{~m}$ & $150 \mathrm{~m}$ & $165 \mathrm{~m}$ & $165 \mathrm{~m}$ & 180 \\
\hline
\end{tabular}

Note: Ses = session; Total $\mathrm{d} .=$ total distance

(b)

\begin{tabular}{ccccc}
\hline Weeks & Week 1 & Week 2 & Week 3 & Week 4 \\
\hline Exercise & Ses 1 - 4 & Ses 1 - 4 & Ses 1 - 4 & Ses 1 - 4 \\
\hline SSB & SSB & SSB & SSB & SSB \\
SSG & SSG & SSG & SSG & SSG \\
\hline Weeks & Week 5 & Week 6 & Week 7 & Weeks 8 - 9 \\
\hline Exercise & Ses 1 - 4 & Ses 1 - 4 & Ses 1 - 4 & Ses 1 - 4 \\
\hline SSB & SSB & SSB & SSB & SSB \\
SSG & SSB & SSB & SSB & SSB \\
\hline
\end{tabular}

Note: Ses = session; SSB = specific soccer drills with the ball; SSG = small sided games.

The technical exercises in the TG included basic running technique drills for different joints, as follows: ankle-low/quick skipping; thigh-high skipping; knee-back heel kicks; shoulder-running arm movement; and running-emphasis on accurate joint actions. Due to the children's lack of experience in this type of training, particular attention was paid to demonstration and execution. Two basic techniques were stressed: 1) correct posture (e.g., spine erect, shoulders back) and body alignment (e.g., chest over knees) as the body moves forward; and 2) soft landings, including toe-to-heel rocking and bent knees. All exercises were adapted to the coordination capacity of the children and performed at gradual speeds. None of the repetitions in each drill lasted more than 8 seconds, to ensure that energy was produced mainly by intramuscular phosphagen de- 
gradation; there was a 90-second rest between sets to allow for resynthesis of phosphagens.

In the two additional weekly training days of the TG, training was devoted to soccer-specific exercises performed with the ball, tactical drills, and small-sided games of 3 - 6 players in each team. The SG performed these exercises in all four soccer sessions of each week. The soccer exercises were similar and matched in terms of intensity and volume between the two training groups.

All training sessions were performed on a grass surface with the players wearing their soccer shoes. Training sessions were performed in the late afternoon, 3 - 4 hours after lunch, with an average air temperature of about $18^{\circ} \mathrm{C}-22^{\circ} \mathrm{C}$. Participants were instructed to drink $500 \mathrm{cc}$ of water $30 \mathrm{~min}$ before each training session.

\section{Testing Procedures}

Participants performed two similar sets of tests before and after the nine-week training period. The first set of tests was conducted on two non-consecutive days during the week prior to the beginning of the training program. The second set of tests was conducted during the week after the completion of the training program. Both sets of tests were performed using the same procedures, at the same time of the day, under the same environmental conditions, and with the same technician, who was blind to the training-group affiliation. Participants were familiar with the testing procedures, as they had performed them on previous occasions. Before each set of tests, participants performed a standard warm-up that included 8 min of jogging, followed by a 10-in stretching exercise, two 20 $\mathrm{m}$ sprints and jumping drills. A 20-min period separated the different tests on each day. All running and jumping tests were performed at the same location and under similar environmental conditions as in the training sessions. Running times were recorded using a photoelectric cell timing system (Alge-Timing Electronic, Vienna, Austria) with an accuracy of $0.001 \mathrm{~s}$, linked to a digital chronoscope. A standing start, with the front foot placed $30 \mathrm{~cm}$ behind the timing lights, was used for all sprints. Timing was initiated when the subject broke the light beam.

On the first day of each testing set, participants performed the following two tests:

Standing Long Jump — Power Test. Horizontal-jump length was measured by a maximum jump using a free countermovement technique (FCMJ). Participants began in an erect standing position and moved into a semi-squat position, then leaned forward before jumping horizontally as far as possible. All jumps were performed in a long-jump pit filled with soft sand located next to the soccer pitch. The participant used a vigorous double-arm swing as he jumped off the ground. There were three trials, and the longest jump achieved was recorded. Jumping length was measured manually using a standard measuring tape (Almuzaini \& Fleck, 2008).

The $4 \times 10 \mathrm{~m}$ Run-Agility Test. The agility test used was the $4 \times 10 \mathrm{~m}$ back 
and forth shuttle run. The participant began at the base line and ran at maximal speed to a marked line that was located $10 \mathrm{~m}$ ahead of him. After touching the line, he turned and ran back to the baseline, touched the line, turned again, and performed the same back and forth run. This procedure was performed twice, and the faster time of the two trials was recorded. The participant rested for 5 min between the two runs. Each participant ran individually (Stølen, et al., 2005).

On the second day, the participants performed the following three tests:

$10 \mathrm{~m}$ Run-Speed Test. A $10 \mathrm{~m}$ all-out sprint run was used to evaluate the participants' power and running start ability. Each participant performed the test individually, while self-started after getting into a standing ready position with the body leaning forward. Two runs were completed, and the better time was recorded. Participants rested for 5 minutes between runs.

$30 \mathrm{~m}$ Run-Speed Test. A $30 \mathrm{~m}$ sprint run was used to evaluate the participants' speed and acceleration ability. Participants self-started after getting into a standing ready position. Two runs were completed, and the better time was recorded. Participants rested for 5 minutes between runs. The test was performed individually by each participant.

Aerobic Capacity Test-Twenty-Meter Shuttle Run Test. The test consisted of shuttle runs at increasing speeds between two markers, placed $20 \mathrm{~m}$ apart (Gibson et al., 1998). A portable compact disc (Sony CFD-V7) dictated the test pace by emitting tones at appropriate intervals. The participant was required to be at one end of the $20 \mathrm{~m}$ course at the signal. A start speed of $8.5 \mathrm{~km} / \mathrm{hour}$ was maintained for one minute, and thereafter the speed was increased every minute by $0.5 \mathrm{~km} /$ hour. The test score for each participant was determined according to the number of laps or the total distance he achieved during the test.

The rationale for the selection of these testing procedures was based on their relevancy to soccer and to the scope of the study. A high test-retest reliability (0.80 - 0.95) of most of the tests used in the study was described previously (Almuzaini \& Fleck, 2008; Gibson et al., 1998; Stølen et al., 2005).

\subsection{Statistical Analysis}

A two-way repeated-measure analysis of variance was used to compare fitness differences, with time serving as the within-group factor and training regimen as the between-group factor. A Cohen's d-effect size (ES) was also performed to demonstrate the magnitude of the training effect in each group. Cohen's $\mathrm{d}<0.30$ was considered a low effect, $0.30-0.70$ a moderate effect, and $>0.70$ a strong effect. The Shapiro-Wilk test was used to ensure normal distribution of the results. Data are presented as the mean \pm SD. Significance level was set at $p \leq 0.05$.

\section{Results}

There were no baseline differences in age (13.5 \pm 6.8 and $13.4 \pm 8.2$ yrs), body mass $(41.8 \pm 6.9$ and $42.3 \pm 6.3 \mathrm{~kg})$, or height $(151.1 \pm 9.8$ and $156.6 \pm 7.6 \mathrm{~cm})$ 
prior to the training between the groups. Changes in anaerobic and aerobic performances following the training programs are presented in Table 2. There were no baseline differences in any of the anaerobic or aerobic test scores prior to the training between the groups. SG training led to a significant improvement only in the $20 \mathrm{~m}$ shuttle run test $(p<0.05)$. In addition, the percent change in the 20 $\mathrm{m}$ shuttle run test was significantly greater in the SG compared to the TG ( $p<$ 0.01 ) (see Figure 1). TG training led to a significant improvement in the $10 \mathrm{~m}$ sprint time $(p<0.05)$ and the $30 \mathrm{~m}$ sprint time $(p<0.05)$, but to a significant reduction in the $4 \times 10 \mathrm{~m}$ time $(p<0.01)$. However, there were no significant between-group differences in the training effects on any of the anaerobic variables measured (Figure 2). Neither of the training programs had a significant effect on the standing long-jump test results. In addition, no significant interaction was found between the training groups in any of the variables that were tested.

Table 2. The effect of the tow training programs on selected anaerobic and aerobic performances (means \pm SD).

\begin{tabular}{cccccccc}
\hline & \multicolumn{3}{c}{$\begin{array}{c}\text { Soccer Group } \\
\text { (SG) N }=14\end{array}$} & \multicolumn{3}{c}{ Technical + Soccer Group } \\
Variable & Pre & Post & ES & Pre & Post & ES & $\begin{array}{c}\text { F intr } \\
\text { F (1, 26) }\end{array}$ \\
\hline Standing long jump (cm) & $172.8 \pm 18.9$ & $178.5 \pm 20.5$ & 0.30 & $186.2 \pm 17.0$ & $185.1 \pm 17.9$ & 0.07 & 3.43 \\
$4 \times 10 \mathrm{~m}(\mathrm{sec})$ & $10.49 \pm 0.49$ & $10.60 \pm 0.40$ & 0.22 & $9.99 \pm 0.43$ & $10.20 \pm 0.42^{* *}$ & 0.49 & 1.03 \\
Run 10 m (sec) & $2.13 \pm 0.14$ & $2.07 \pm 0.27$ & 0.42 & $2.05 \pm 0.08$ & $2.00 \pm 0.09^{*}$ & 0.63 & 0.01 \\
Run 30 m (sec) & $5.36 \pm 0.39$ & $5.31 \pm 0.29$ & 0.12 & $5.13 \pm 0.23$ & $5.07 \pm 0.26^{*}$ & 0.27 & 0.03 \\
$20 \mathrm{~m}$ shuttle run (m) & $645 \pm 362$ & $738 \pm 308^{*}$ & 0.25 & $650 \pm 269$ & $630 \pm 363$ & -0.07 & 0.69 \\
\hline
\end{tabular}

Note: ${ }^{*} p<0.05$ for within group changes; ${ }^{* *} p<0.01$ for within group change; ES: effect size.

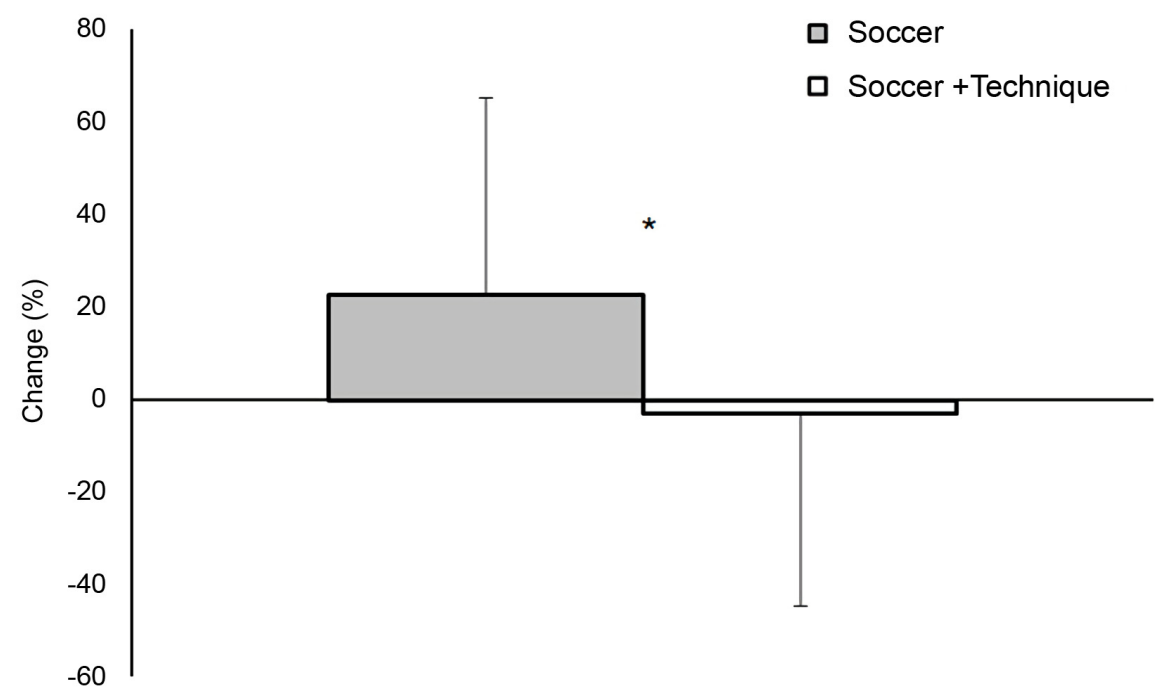

Figure 1. The effect of the two training programs on percent change of the $20 \mathrm{~m}$ shuttle run test results. ${ }^{\star} p<0.01$ for between group change. 


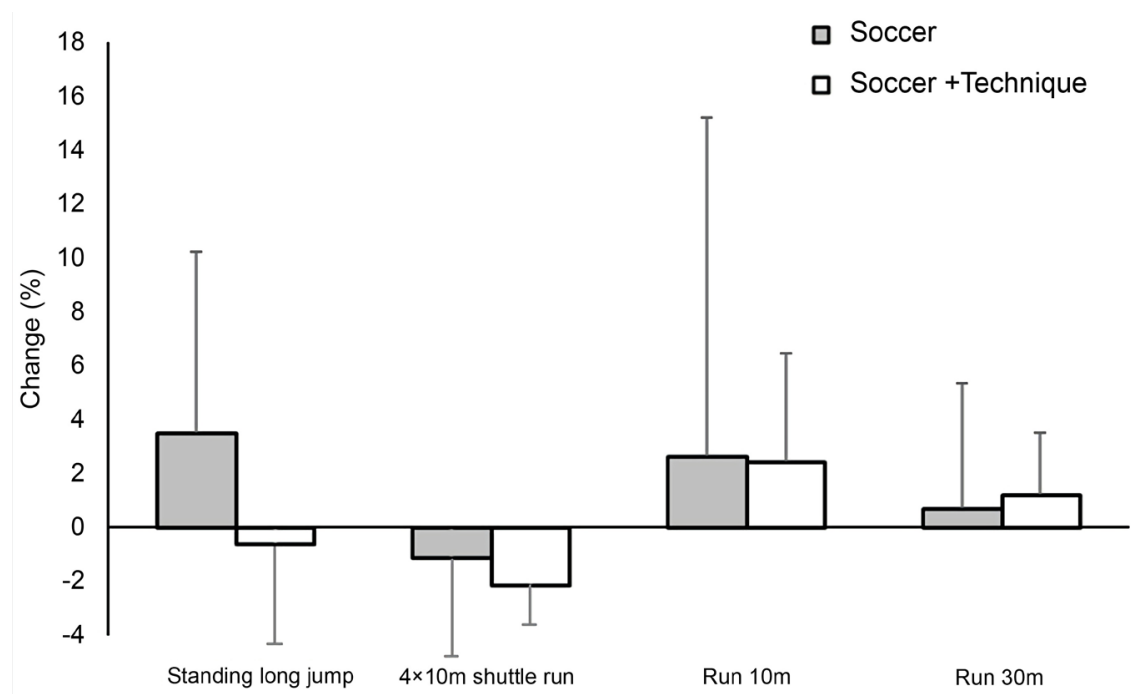

Figure 2. The effect of the two training programs on percent changes of selected anaerobic performances.

\section{Discussion}

The findings of the present study revealed inconsistency as to the effectiveness of the two training programs, demonstrating the complexity of the performance requirements in the game. While the TG showed significant improvement in the $10 \mathrm{~m}$ and the $30 \mathrm{~m}$ sprint runs with no such improvement for the SG, significant improvement was found in the aerobic capacity for the SG with no such change for the TG. Neither of the training programs induced significant effects in the long-jump test. In addition, significant deterioration was found in the $4 \times 10 \mathrm{~m}$ agility test for the TG, with no change in this variable for the SG.

These results are partially in contrast to our hypothesis and to several previous studies showing that short-term technique training has a consistent positive effect on fitness components such as power, speed, and agility among children (e.g., Branta, Haubenstricker, \& Seefeldt, 1984; Venturelli, Bishop, \& Pettene, 2008). It was suggested that this improvement resulted mainly from neural adaptations. Although this adaptation is dependent on the specific training variables (e.g., volume, intensity, and complexity of drills), it generally consists of selective activation of muscles, selective activation of motor units, synchronization, and improved intermuscular coordination (Markovic \& Mikulic, 2010).

When evaluating the effectiveness of the technical training program in the present study, certain methodological and physiological elements should be considered. First, some of the testing procedures that were used in the present study required fitness components, such as muscle power and strength (e.g., the standing long jump test) rather than just specific motor skills (Markovic \& Mikulic, 2010). In light of the present results, it is possible that the SG training, involving activities such as acceleration, stopping, pushing, and tackling during the small-sided games and the soccer-specific drills, may have produced greater muscle strength and power than the TG, which performed relatively low intensity activity during 
the technical drills. Although no significant interaction was found between the groups in the long-jump power test, the differences between the training programs' characteristics may have caused different responses in this test between the groups (see Table 2). In line with this, an improvement of $6.0 \%$ was found in standing long-jump scores of 12- to 15-year-old boys following a six-week training program that combined technical exercises with weight-lifting training (Faigenbaum et al., 2007). It may therefore be recommended that for significant improvement in power performances such as horizontal or vertical jumps, specific resistance training should be included in the weekly training schedule.

The significant deterioration in the $4 \times 10 \mathrm{~m}$ agility test in the TG was a surprise and in contrast to our hypothesis. Previous studies have found significant improvement in agility of children following short-term training programs that involved technical and motor control drills (Altinkök, 2016; Branta, Haubenstricker, \& Seefeldt, 1984; Smits-Engelsmana, Jelsmab, \& Ferguson, 2017). However, the participants in these studies were sedentary children with no previous involvement in training program. Although the children in the present study did not experienced a systematized technical training program before, they were certainly familiar with activities such as change of direction or with back and forth running that are highly typical to soccer. It, therefore, reasonable to assume that the agility-level starting point of these players was already high at the beginning of the present study leaving only minor room for improvement in the $4 \times 10 \mathrm{~m}$ agility test performance of both training groups. The significant decrease in the $4 \times 10$ $\mathrm{m}$ test score of the TG may be relates to the fact that the technical drills in this group were performed only in a unidirectional fashion without turning points or change of direction. In that regard, Young, James, \& Montgomery (2002) suggested that agility tasks could be more influenced by specific motor control factors than by muscle strength and power activity. Furthermore, in young children, the improvement of muscle power depends on neural factors rather than muscle strength (Thomas, French, \& Hayes, 2009). Given the results of the present study, these neural factors should probably be stimulated and practiced in specific drills that relate to the specific sport or testing procedures used. Obviously, the issue of specific technical exercises for improving agility and quickness among children needs to be clarified in future studies.

All-out sprinting represents a complex movement that requires a high level of neuron activation (Markovic et al., 2007; Matavulj et al., 2001; Nicol, Avela, \& Komi, 2006; Ross, Leveritt, \& Riek, 2001). It was previously shown that increased nerve activation, together with frequency or degree of muscle innervation, was associated with specific technical training, especially in young populations (Markovic \& Mikulic, 2010). Differences in running technique and in muscle activation patterns have also been reported among trained sprinters, and included sprint-specific technical drills in their training compared with controls (Ross, Leveritt, \& Riek, 2001). In agreement with these and with our hypothesis, the 10 $\mathrm{m}$ and the $30 \mathrm{~m}$ sprint results in the present study were improved significantly in 
the TG, whereas the improvement in the SG did not reach a significant level (see Table 2). Although we did not assess neuron adaptation, these results may confirm that a general adaptation phase of basic technical training is essential for young soccer players in order to improve sprint performances. This is consistent with previous studies reporting significant improvement in technique-related performances such as in sprint running following training programs that included technical exercises (Bojić \& Pavlović, 2015; Ross, Leveritt, \& Riek, 2001). Moreover, general technical training in 11-year-old soccer players was found to increase specific soccer skills such as sprinting with ball, more than sprint training alone (Venturelli, Bishop, \& Pettene, 2008). Similar results were found for 13-year-old male soccer players (Branta, Haubenstricker, \& Seefeldt, 1984) and for 12 - 14-year-old young female handball players (Bojić \& Pavlović, 2015). The investigators in these studies suggested that technical training provides a greater neural stimulus, resulting in better intramuscular and intermuscular coordination for sprint running.

The $20 \mathrm{~m}$ shuttle run ("yo-yo") test results-as an indicator of the participants" aerobic capacity in the present study-showed a significant improvement in the SG, with no such improvement in the TG (Table 2). The improvement in aerobic capacity was significantly different between the groups (see Figure 1). The significant superiority of the SG over the TG in aerobic improvement can probably be attributed to the nature of the training in the two groups. As described earlier, while the TG implemented low-intensity coordination drills into their training sessions, the SG performed relatively high-intensity soccer training, consisting of small-sided games, in all weekly training sessions. Given the differences in training intensity between the two groups, the significant difference in the aerobic capacity changes between the groups may be reasonable. Furthermore, the use of the $20 \mathrm{~m}$ shuttle run test, which replicates soccer-specific activity, as the evaluating procedure for the players' aerobic capacity in the present study, may have had a positive impact on the SG scores compared to the TG scores. The significant aerobic superiority of the SG over the TG following training should be taken into consideration by coaches since it may indicate that the inclusion of low-intensity exercises such as technical drills on the account of high-intensity soccer-specific exercises may interfere with the players' desired aerobic capacity.

One limitation of the present study may be that our groups sample sizes were relatively small. This was the result of a $20 \%$ dropout rate of players who missed testing or training sessions. In addition, changes in some of the anaerobic performances that were measured in the present study could have reflected changes in muscle power and strength rather than motor skills. The use of special and specific testing procedures that rely and reflect specific motor skills could have been more appropriate for the purpose of the study. Furthermore, level of intensity and volume of activity was not monitored during training. This prevented an accurate comparison between the two training protocols. 


\section{Conclusion}

In conclusion, given the complexity and the various requirements of soccer, it can be suggested that in order to comply with all game requirements, technical training programs for young players may be more efficient if implemented together with other fitness agendas. Among these are resistance exercises that may improve soccer-specific actions such as jumping, accelerating, and changing of running direction. In addition, the implementation of aerobic-oriented type drills should be considered, given the low intensity of technical drills and the possible reduction in aerobic capacity. Future studies may examine the effect of technical training programs on players of different age groups. In addition, different technical drills, of different complexity and volume may be applied in future studies in order to examine their impact on young soccer players.

\section{Acknowledgements}

The authors wish to thank the Modiin Youth Soccer Club for its cooperation in this study. The authors also wish to thank each of the players and the coaches for their efforts in performing the physical tasks needed for the study.

\section{Conflicts of Interest}

The authors declare no conflicts of interest regarding the publication of this paper.

\section{References}

Almuzaini, K. S., \& Fleck, S. J. (2008). Modification of the Standing Long Jump Test Enhances Ability to Predict Anaerobic Performance. Journal of Strength and Conditioning Research, 22, 1265-1272. https://doi.org/10.1519/JSC.0b013e3181739838

Altinkök, M. (2016). The Effects of Coordination and Movement Education on Pre School Children's Basic Motor Skills Improvement. Universal Journal Educational Research, 4, 1050-1058. https://doi.org/10.13189/ujer.2016.040515

Bojić, I., \& Pavlović, L. (2015). Correlation between Coordination and Situational-Motor Abilities of Young Female Handball Players. Research in Physcal Education, Sport and Health, 4, 105-110.

Branta, C., Haubenstricker, J., \& Seefeldt, V. (1984). Age Changes in Motor Skills during Childhood and Adolescence. Exercise and Sport Sciences Reviews, 12, 467-420. https://doi.org/10.1249/00003677-198401000-00015

De Villarreal, E. S., Suarez-Arrones, L., Requena, B., Haff, G. G., \& Ferrete, C. (2015). Effects of Plyometric and Sprint Training on Physical and Technical Skill Performance in Adolescent Soccer Players. Journal of Strength and Conditioning Research, 7, 1894-1903. https://doi.org/10.1519/JSC.0000000000000838

Faigenbaum, A. D., McFarland, J. E., Keiper, F. B., Tevlin, W., Ratamess, N. A., Kang, J., \& Hoffman, J. R. (2007). Effects of Short-Term Plyometric and Resistance Training Program on Fitness Performance in Boys Age 12 to 15 Years. Sports Science Medicine, 6, 519-525.

Gibson, A., Broomhead, S., Lambert, M. I., \& Hawley, J. A. (1998). Prediction of Maximal Oxygen Uptake from a $20 \mathrm{~m}$ Shuttle Run as Measured Directly in Runners and Squash Players. Sports Science, 16, 331-335. https://doi.org/10.1080/02640419808559361

Malina, R. M., Ribeiro, B., Aroso, J., \& Cumming, S. P. (2007). Characteristics of Youth Soccer Players Aged 13 - 15 Years Classified by Skill Level. British Journal of Sports 
Medicine, 41, 290-295. https://doi.org/10.1136/bjsm.2006.031294

Markovic, G., \& Mikulic, P. (2010). Neuro-Musculoskeletal and Performance Adaptations to Lower-Extremity Plyometric Training. Sports Medicine, 40, 859-865.

https://doi.org/10.2165/11318370-000000000-00000

Markovic, G., Jukic, I., Milanovic, D., \& Metikos, D. (2007). Effects of Sprint and Plyometric Training on Muscle Function and Athletic Performance. Journal of Strength and Conditioning Research, 21, 543-549. https://doi.org/10.1519/00124278-200705000-00044

Matavulj, D., Kukolj, M., Ugarkovic, D., Tihanyi, J., \& Jaric, S. (2001). Effects of Plyometric Training on Jumping Performance in Junior Basketball Players. Sports Medicine and Physical Fitness, 41, 159-164.

Meckel, Y., Gefen, Y., Nemet, D., \& Eliakim, A. (2012). Influence of Short versus Long Repetition Sprint Training on Selected Fitness Components in Young Soccer Players. Journal of Strength and Conditioning Research, 26, 1845-1851. https://doi.org/10.1519/JSC.0b013e318236d0f0

Naughton, G., Farpour-Lambert, N. J., Carlson, J., Bradney, M., \& Van Preegh, E. (2000). Physiological Issues Surrounding the Performance of Adolescent Athletes. Sports Medicine, 30, 309-325. https://doi.org/10.2165/00007256-200030050-00001

Nicol, C., Avela, J., \& Komi, P. V. (2006). The Stretch-Shortening Cycle: A Model to Study Naturally Occurring Neuromuscular Fatigue. Sports Medicine, 36, 977-999. ttps://doi.org/10.2165/00007256-200636110-00004

Rampinini, E., Coutts, A. J., Costagna, C., Sassi, R., \& Impellizzeri, F. M. (2007). Variation in Top Level Soccer Match Performance. International Journal of Sports Medicine, 28, 1018-1024. https://doi.org/10.1055/s-2007-965158

Ross, A., Leveritt, M., \& Riek, S. (2001). Neural Influences on Sprint Running: Training Adaptations and Acute Responses. Sports Medicine, 31, 409-425. https://doi.org/10.2165/00007256-200131060-00002

Smits-Engelsmana, B. C. M., Jelsmab, D. L., \& Ferguson, G. D. (2017). The Effect of Exergames on Functional Strength, Anaerobic Fitness, Balance and Agility in Children with and without Motor Coordination Difficulties Living in Low-Income Communities. Human Movement Science, 55, 327-337. https://doi.org/10.1016/j.humov.2016.07.006

Stølen, T., Chamari, K., Castagna, C., \& Wisløff, U. (2005). Physiology of Soccer. Sports Medicine, 35, 501-536. https://doi.org/10.2165/00007256-200535060-00004

Thomas, K., French, D., \& Hayes, P. R. (2009). The Effect of Two Plyometric Training Techniques on Muscular Power and Agility in Youth Soccer Players. Journal of Strength and Conditioning Research, 23, 441-445. https://doi.org/10.1519/JSC.0b013e318183a01a

Velickovic, V. (2012). Relations between Coordination and Situational-Motor Tests of Soccer Players. Activities in Physical Education \& Sport, 2, 73-75.

Venturelli, M., Bishop, D., \& Pettene, L. (2008). Sprint Training in Preadolescent Soccer Players. Sports Physiology and Performance, 3, 558-562.

https://doi.org/10.1123/ijspp.3.4.558

Yasumitsu, T., \& Nogaw, H. (2013). Effects of a Short-Term Coordination Exercise Program during School Recess: Agility of Seven- to Eight-Year-Old Elementary School Children. Perceptual and Motor Skills, 116, 598-610.

https://doi.org/10.2466/25.10.PMS.116.2.598-610

Young, W. B., James, R., \& Montgomery, I. (2002). Is Muscle Power Related to Running Speed with Changes of Direction? Sports Medicine and Physical Fitness, 42, 282-288. 